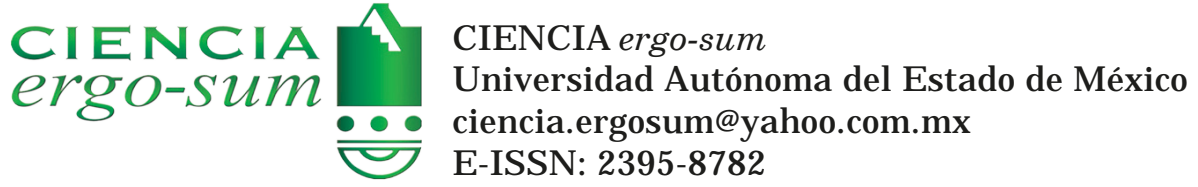

\title{
Some implications of an epistemic-intersubjective interpretation of the "beyond all reasonable doubt" standard of proof for criminal investigations
}

\section{R. Aguilera, Edgar}

Some implications of an epistemic-intersubjective interpretation of the "beyond all reasonable doubt" standard of proof for criminal investigations

CIENCIA ergo-sum, vol. 27, núm. 2, julio-octubre 2020|e89

Universidad Autónoma del Estado de México, México

Esta obra está bajo una Licencia Creative Commons Atribución-NoComercial-SinDerivar 4.0 Internacional .

R. Aguilera, E. (2020). Some implications of an epistemic-intersubjective interpretation of the "beyond all reasonable doubt" standard of proof for criminal investigations. CIE NCIA ergo-sum, 27(2). https://doi.org/10.30878/ces.v27n2a10 


\title{
Some implications of an epistemic-intersubjective interpretation of the "beyond all reasonable doubt" standard of proof for criminal investigations
}

Algunas implicaciones de una interpretación epistémico-intersubjetiva del estándar de "prueba más allá de toda duda razonable" para la investigación del delito

Edgar R. Aguilera

Universidad Autónoma del Estado de México, México

Recepción: 27 de mayo de 2019

edgar.aguilera@udg.edu

Aprobación: 15 de agosto de 2019

(DD http://orcid.org/0000-0003-0119-0515

\begin{abstract}
The essay introduces Professor Ferrer's proposal to endow the widely employed criminal standard of proof of guilt beyond all reasonable doubt, with epistemic-intersubjective (as opposed to psychological-subjective) content. In analyzing the positive implications of adhering to this interpretation, the author argues it is a promising way to start eroding Mexico's authoritarian model of criminal investigation, and to put in place an innocence-disproving culture instead.
\end{abstract}

KEYWORDS: beyond all reasonable doubt, standard of proof, criminal investigation, evidential reasoning.

\section{RESUMEN}

Se presenta la propuesta del profesor Ferrer de dotar de contenido epistémico-intersubjetivo al ampliamente usado estándar de prueba penal que autoriza una condena sólo si se ha demostrado la culpabilidad del acusado más allá de toda duda razonable. Se argumenta que entre los efectos positivos de optar por esta interpretación yace su potencial de contribuir a la implementación de una cultura menos inquisitoria y, por ende, al desmantelamiento progresivo del modelo autoritario de investigación que, pese a las reformas recientemente experimentadas, arrastra a cuestas el sistema mexicano de administración de justicia.

Palabras Clave: más allá de toda duda razonable, estándar de prueba, investigación del delito, razonamiento probatorio.

\section{INTRODUCTION: A FIRST GLANCE AT “CONVICTION BEYOND ALL REASONABLE DOUBT” AS THE STANDARD OF PROOF IN MEXICO'S CRIMINAL PROCEDURE}

Article 402's third paragraph of the Mexican National Code of Criminal Proceedings asserts the Trial Court must be convinced beyond all reasonable doubt that the accused is responsible for committing the crime (or crimes) she was charged with, before rendering a guilty verdict.

These words sound very nice and appealing, but once we spend a little time reflecting upon them, the promise of protection against the abuse of the State's coercive power they seem to make, starts losing its glow. This is because nobody (not even the relevant legal operators such as judges, lawyers, and scholars, and not even in the Common Law tradition where this standard of proof $[1]$ was originated) seems to have a clue pertaining to the meaning of the mysterious phrase "conviction beyond all reasonable doubt", apart from the very general notion that it mandates the trier of fact ${ }^{[2]}$ to be very sure concerning the accused's guilt (Laudan, 2013: 59-102). [3]

In contemporary western societies it has become widely accepted (at least, in theory) that, if a criminal conviction is in order, among other things, we want our triers of fact (whether juries or professional judges) to be very sure about the accused's guilt, based on the assumption that meeting this demand will contribute to thoroughly 
minimizing the risk of convicting the innocent. ${ }^{[4]}$ The problem is that this noble effort is a non-starter if we are not able to convey accurately to those triers of fact, the level of certainty (and more precisely, of inductive or logical probability) required by the above mysterious phrase.

\section{Clarifying the criminal standard of Proof: The main proposal}

How then can we solve this conundrum? Where can we look for guidance in this regard? Fortunately, the so-called rationalist tradition of legal proof, the main tenets of which I adhere to, has been advancing some promising proposals. Here I will focus on Professor Jordi Ferrer's approach according to which proof beyond all reasonable doubt (or BARD for short and hereafter) can be read as entailing the following (Ferrer, 2007: 144-152):

a) The guilt hypothesis must be able to explain the available facts, evidence or data by way of integrating them in a coherent account of the criminal event (which usually takes the form of a story or narrative whose episodes are ordered according to chronological and causal considerations);

b) The most important and empirically testable predictions a reasonable person may draw from the guilt hypothesis, must be confirmed, and:

c) All the plausible, non-ad hoc, and innocence-pointing hypotheses explaining the same pivotal facts, evidence or data, must be refuted, that is, the most important predictions a reasonable person may draw from each of those hypotheses should be disconfirmed. [5]

\section{THE PROPOSAL'S ADVANTAGES OVER SUBJECTIVE INTERPRETATIONS OF THE CRIMINAL STANDARD OF PROOF}

Some skeptics towards the above proposal complain that it does not fully dispel the uncertainty surrounding the BARD standard. I will take up the discussion with them at the end of this section. For now, and given our immediate purposes, it is harmless to agree with such a position. Indeed, as long as this interpretation of the BARD standard is articulated using language, and as long as language suffers from indeterminacy, ambiguity and vagueness in various degrees, there remains a margin (a small one though, or so is argued) for discretion, and even for unguided plain arbitrariness. Nonetheless, this proposal pays a great service at recasting the problems of evidence evaluation and evidence sufficiency for asserting some proposition as proven, in non-subjective terms $[6]$ (hence, reversing the tendency to treat these problems from a psychological-subjective standpoint).

Think of it this way: In the unfortunate case you have been accused of a crime, gone to trial, and have been waiting for the Court's decision, assuming that you are materially innocent (which is to say that, as a matter of fact, you were in no way involved in the commission of the criminal event for which the prosecutor wants the trier of fact to find you guilty and the judge to sentence you), would you be willing to put yourself at the expense of the influence that non-epistemic (or non-evidentiary) reasons, prejudices among them, may exert on the trier of fact's deliberation?

I reckon your answer would be no. But this is precisely what could happen when the criterion to determine if the evidence adduced at trial is sufficient or not, instead of pointing to the features the evidence should have, or to the inferential processes the trier of fact should engage in when she goes about assessing the evidence (Picinali, 2015), entrusts her to make an introspective journey to detect whether she experiences a certain kind of mental state, like the intense belief that you are guilty or the conviction BARD that you committed the crime. If the trier of fact's mental trajectory is transparent to herself (which is already doubtful), and if she is honest, she may come to realize that the main reason explaining (as opposed to justifying) why she so firmly believes you are guilty, might simply be that you strike her as a very bad person (may be because of the social group you belong to). To the extent she has acquired the specified mental state, regardless of the factors causing her to have it, the 
criterion has been satisfied, thus paving the way for a guilty verdict to be legally valid (and legally required). It would not matter if the trier of fact were cautious enough to state that she came to possess the intense belief or conviction that you are guilty "based on the available evidence". Even if she thinks the words she just added make for a more objective and reliable deliberation on her behalf, the fact of the matter is that, in light of this criterion of evidence sufficiency, if it is true she came to strongly believe in your guilt via the available evidence, that is simply irrelevant. "I am fully (deeply, firmly, or totally) convinced of the accused's guilt" is all she needs to assert in order for us to take her as having appropriately discharged her fact-finding duties.

I am not denying that the available evidence may have in deed performed some role in triggering the trier of fact's firm belief in your guilt, thus endowing her with a certain degree of warrant or justification. The point is that, as long as it is possible for different triers of fact to react differently when faced with the same evidence, even those who concluded their deliberations without having the intense belief that you are guilty would be correctly applying this criterion of evidence sufficiency if they acquit (as they should in this circumstances), due to the fact that, viewed as a decision rule, it demands from the trier of fact to render a guilty verdict if and only if she experiences the above mental state, and to render an acquittal otherwise. Where I am trying to get is that, as long as they sincerely report the possession of the mental state that consists of believing firmly in the accused's guilt (or their lack thereof), no trier of fact could ever be legally wrong in discharging her fact-finding duties according to this criterion. And if that is the case, we can start saying farewell to the legitimate social expectations of due process, legal certainty, and uniformity in criminal adjudication across similar cases.

Turning back to the skeptics I referred to at the beginning of this section, it is time to take their position into brief (due to space constraints), but to the extent of my abilities, serious consideration. In my opinion, the most compelling doubts regarding the plausibility of the project outlined in section 1, have been advanced by Professor Bayón (Bayón, 2008). His argumentative itinerary is highly complex, and given the panoramic nature of this essay, I cannot reproduce here all its sophisticated details. Suffice it to say that one of his main worries is that the hypothetical-deductive method (which is, in principle, very similar to Ferrer's proposal regarding how to interpret the BARD standard and regarding the intellectual operations involved in determining whether the standard has been met), may not be suitable for the criminal procedure context. His point is that once a case has reached the deliberation stage, the trier of fact cannot subject the hypotheses put forward by the parties (mainly by the prosecution) to further test, which is a crucial feature that the hypothetical-deductive model seems to imply. But, it is not the trier of fact's job to ask herself what other pieces of evidence (in addition to those already introduced and heard at trial) could be expected to be found if the parties' theories were right, and to determine if such "new" predictions are confirmed or disconfirmed. The trier of fact is confined to the exclusive consideration of the evidence already at hand; in that sense, she carries out her task in a "closed setting" where the legally obtained evidence reproduced at trial is the only evidence she can work with. I agree with Professor Bayón. He is right in holding that in this stage, the trier of fact (at least in accord with our current legal frameworks), cannot be granted the powers of asking for the production of more evidence in order to keep testing the parties' theories of the case. In effect, this would amount to reopening the investigation phase which is supposed to have ended at this point. The problem with Bayón's skeptical stance is that this is not required by Ferrer's proposal. What the standard outlined in section 1 really requires, is for the trier of fact to draw the main evidential predictions that a reasonable person may also draw from the guilt and the innocence-pointing hypotheses, to check which of those predictions are confirmed or disconfirmed by the evidence already available (as opposed to expecting for more information to be supplied in the future), and, more importantly, to hold against the State — in the sense of rendering an acquittal —, the fact that some important prediction(s) of the guilt hypothesis had not been confirmed,[7] and/or the fact that some main predictions drawn from the innocence-pointing hypothesis (or hypotheses) had been confirmed, $[8]$ and/or the fact that there may be no information available on which to base the determination whether certain main guilt or innocence-pointing predictions are confirmed or disconfirmed. [9] 
As I said before, the standard outlined in section 1 does not fully dispel the uncertainty surrounding the mysterious phrase "beyond all reasonable doubt". Indeed, there will inevitably be some space for disputes to arise with respect to the status of the predictions that may be drawn from the hypotheses at play, i. e., is this particular prediction pivotal to the case or is it just a peripheral or unimportant one? In other words, and to conclude with this section, the rationalist tradition of legal proof is not in the business of producing an algorithm-like and infallible instruction to substitute the excessively vague standards of proof such as BARD, but in the business of reasonably reducing their hale of indeterminacy, and of relocating our focus upon the features the evidence must have and on the intellectual operations the trier of fact should engage in when she goes about assessing that evidence, instead of chasing subjective mental states. But even if these efforts are successful with respect to this modest objective, articulating a particular standard of proof (the job of the legislator, ideally supported by legal scholars) and determining whether it has been met in particular cases (the job of the trier of fact), will remain being complicated tasks where frontier cases somehow will have to be dealt with. No recipe is foreseeable in the near, nor in the distant future, and perhaps, no recipe is desirable.

\section{Alternative proposals, Same Basic CONTENT}

Other proposals to clarify the BARD standard of proof in the right direction [10] have been put forward. Here I will refer to the following (Laudan, 2013: 126-134):

a) If there is credible, inculpatory evidence or testimony that would be very hard to explain if the defendant were innocent, and no credible, exculpatory evidence or testimony that would be very difficult to explain if the defendant were guilty, then convict; otherwise, acquit.

b) Figure out whether the facts established by the prosecution rule out every reasonable hypothesis you can think of that would leave the defendant innocent. If they do, convict; otherwise, acquit.

What I want to emphasize about both standards is that they mandate the trier of fact to perform what I take to be the same inferential tasks, which are arguably specified more adequately in Ferrer's proposal. Let us elaborate on this point:

In the case of A, "credible, inculpatory evidence or testimony that would be very hard to explain if the defendant were innocent" is evidence or testimony inconsistent with an innocence-pointing hypothesis, that is, evidence or testimony the absence of which may be reasonably predicted if the innocence-pointing theory under consideration were true. Therefore, that the prosecutor was able to collect and introduce such evidence and testimony in the context of the trial disconfirms exculpatory theories of the case. And the same happens with "exculpatory evidence or testimony that would be very difficult to explain if the defendant were guilty". What makes the evidence and testimony very difficult to explain if the defendant were guilty is the fact that the prosecutor' $s$ theory allows us to predict its absence.

In the case of the standard B, the trier of fact is in a better position to figure out if the facts established by the prosecution "rule out every reasonable hypothesis that would leave the defendant innocent", precisely by determining whether the innocence-pointing hypotheses' main predictions have been disconfirmed.

If this analysis is correct, applying standards $\mathrm{A}$ and $\mathrm{B}$ boils down to being proficient at carrying out the basic intellectual operations of identifying what we might expect from the guilt and innocence-pointing hypotheses in terms of other facts that should have to be obtained if those hypotheses were true, and of determining whether those expectations are confirmed. These basic intellectual operations are what testing hypotheses essentially consists of. But before we can put them to the test, we must have come up with some hypotheses to begin with. We do this by reasoning abductively, which is the topic of the following epigraph. 


\section{Abductive reasoning as a key feature}

In order to be able to apply the standard of proof introduced in section 1, the trier of fact, but more importantly, the criminal investigator or team of investigators, must have developed their abductive reasoning skills (Carson, 2009). Very succinctly, abduction is the intellectual process by which we humans, reason from effects (that is, from what we observe) to their unobserved possible causes. The philosopher Charles Sanders Peirce is credited with the most famous and accurate analysis of abduction. To explain this type of reasoning, he devised the following scheme (Woods, 2015: 209-211):

a) The surprising or anomalous fact $\mathrm{C}$ is observed.

b) But if A were true, $\mathrm{C}$ would be a matter of course (it would lose its anomalous or surprising status).

c) Hence, there is reason to suspect $\mathrm{A}$ is true.

The scheme's second premise contains the hypothesis that the agent ${ }^{[11]}$ facing $\mathrm{C}$ is able to advance (to herself or to others). She comes up with this hypothesis (normally, after a period of reflection, the duration of which is dependent on multiple factors such as, for example, her level of creativity or how odd the surprising event is), precisely in an attempt to dispel her ignorance regarding what could have caused the state of affairs $\mathrm{C}$ she ran into. Hence, there is an explanatory link between $\mathrm{A}$ and $\mathrm{C}$ that, for its part, is based on the following reasoning structure: If the facts, events, or states of affairs that the hypothesis postulates had really taken place, the observed fact $\mathrm{C}$ of the first premise would be part of how things would unfold naturally, assuming a scenario such as the one captured in A has obtained. In other words, the scheme's element A explains element $\mathrm{C}$ (and, for that reason, $\mathrm{C}$ starts losing its surprising or anomalous status), to the extent $\mathrm{C}$ falls within the range of reasonable predictions an agent would draw from the hypothesis.

The question we face at this point is: how is the agent able to determine whether $\mathrm{C}$ falls within the range of reasonable predictions of $\mathrm{A}$ ? The answer is by consulting her empirical generalizations base, which she (and normally every human being) has developed throughout her life on account of her own and/or others' experience. These generalizations have (or may be deployed as having) a conditional form comprised of an antecedent and a consequent.

To sum up, when an agent runs into a surprising event, and in order to start dissipating the hale of mystery surrounding it by way of concocting a hypothesis, she must check whether the observed facts are an instance of the types of facts performing the role of consequents in some empirical generalization she has access to. To the extent she detects this match (which involves a sort of backwards reasoning), she is now equipped with a candidate to explain (to herself or to others) the aspect of the world producing her initial perplexity.

Recall now that the above Peircean scheme's conclusion states that given its premises, we have reason to suspect A is true. Suspecting A is true does not amount to the agent's being justified in believing A, and much less to having knowledge of A. Suspecting A is true is, thus, a very modest cognitive claim. Why is it so modest? Because it is always a possibility that the agent detects more than one match between the surprising fact she ran into and the consequent of an empirical generalization (or an "experience's maxim" as lawyers sometimes call it). This is to say that the observed anomalous facts may be compatible with two or more hypotheses. [12] How must an agent proceed from here?

Briefly, by testing the hypotheses, that is, she must keep asking herself what propositions should also be true apart from the one describing the initial surprising event, which amounts to asking what other predictions the hypothesis so far mustered allows her to infer and whether those predictions have been confirmed. She must, of course, do the same with the alternative hypotheses. She will ideally reach a point where, based on how many important predictions have been confirmed and/or disconfirmed, she will be able to point to the hypothesis favored by a greater inductive support. 


\section{Some Prospective considerations in the CONTEXT OF MeXico's CRIMINal JUSTICE SYSTEM}

Mexico carries a historical and very heavy burden on its back pertaining to criminal justice. This burden amounts to a deeply rooted authoritarian model of criminal investigation. This is a fact acknowledged not only by legal scholars, but by key public servants too (Pérez Correa, 2015). For space constraints, here I can barely highlight the salient aspects of this model, which are 1) the steady recourse to questionable (and, of course, illegal and unconstitutional) methods such as torture, evidence planting, and crime scene tampering, all of which speaks to a lacking in, or to an unwillingness to display, genuine and impartial investigative skills, and in tight connection with this 2) the practice of presuming, not the accused's innocence (as it is constitutionally required), but her guilt, as the driving force of investigations.

We can recast the model's salient feature 2) in terms of the institutionalization of the cognitive biases known as tunnel vision (Findley, 2006; Rassin, 2010) and confirmation bias (Rassin et al., 2010). Very briefly, the former amounts to sticking with, and hastily acting upon, the first and sometimes almost automatically and even unconsciously mustered guess when interpreting some fact, event or state of affairs; while the latter amounts to solely collecting evidence consistent with our initial conjecture (thus, strengthening the illusion that it is rationally supported), avoiding being exposed to sources of information that could contradict or conflict with said original guess, overrating evidence supporting our case and underrating items that speak to the contrary, and even positively assessing evidence against our position.

I submit this state of affairs is reversible. Some steps are crucial to that effect. Here I will focus on the following:

a) Because of the problems they pose to due process and legal certainty, we should do away with subjective readings of the BARD standard of proof, and use standards such as those discussed in section 3 instead, and preferably, the standard introduced in section 1 , on the grounds that it arguably hits the mark in terms of more adequately specifying the intellectual operations that are common to all of them.

b) We should put in place a procedural rule instructing the pre-trial phase judge to determine whether the evidence produced by both parties (the prosecution and the defendant) has the appropriate weight, that is, whether the evidence so far collected (and having overcome other filters), contains enough information so as to eventually allow the trier of fact to determine that the standard of proof has been met. The main question the pre-trial judge has to ask at this stage is this: Is the evidence sufficient to make it likely (more likely than not) that a reasonable person eventually concludes that all the predictions drawn from the guilt hypothesis have been confirmed and all the predictions drawn from all the plausible, non-ad hoc, and innocence-pointing hypotheses have been disconfirmed? Only when the answer is affirmative should the case move forward to the next stages, mainly, the trial. This scenario differs from the current practice where, after concluding with the so-called formal investigation phase, and having established - arguably more likely than not (that is, by a preponderance of the evidence) - that the accused committed the crime, the prosecution may move forward to the intermediate phase, and to the trial, without anybody checking whether the evidence supporting her theory of the case actually has a good chance to raise its strength so it can meet the BARD standard. This state of affairs is perfectly consistent with a subjective reading of $\mathrm{BARD}$ in the sense that once the prosecution has produced a significant amount of inculpatory evidence, she can only hope it will be enough to trigger the firm belief in the accused's guilt in the minds of the triers of fact, just as it triggered that state in her own mind. But as we have said earlier, the possibility remains that, in psychological terms, people react differently when faced with the same amount and quality of evidence. And this is one of the reasons why we need to distance the trier of fact (and anyone in charge of making factual determinations in criminal proceedings) from the psychological-subjective realm, and lead her into the epistemic-intersubjective arena, which we contribute to achieve, I submit, by defining the BARD standard in the terms described in section. 
c) When training the justice system's operators, mainly, criminal investigators, the respective courses should be designed with an eye to prioritizing investigative skills to be institutionally installed (Carson, 2013), instead of emphasizing how to fill out forms and other types of documents (which evidently is important, but not essential to the investigator's profile). Hypotheses generation and testing are, of course, among those investigative skills. Mastering both, and having someone monitoring their correct display, will likely contribute to gradually dismantle the practice of presuming the suspect's or the accused's guilt. In fact, in order for any inculpatory theory of the case to be successful in terms of having what it takes to surpass the different evidence sufficiency thresholds set out throughout the procedure, and mainly the BARD standard as we have proposed to interpret its requirements, criminal investigators and prosecutors must develop an innocence-disproving culture (Carson, 2007), where performing the devil's advocate role (which in this case amounts to assuming the defendant's perspective) comes as naturally as breathing; specially, at the early stages of their investigations, and when their inculpatory theories start getting confirmation by way of having their main predictions verified. This is a critical moment because it is the point in time where the investigations may go into case-construction mode (Rossmo, 2009). To avoid that outcome investigators and prosecutors should ask themselves questions such as the following: What innocence-pointing hypothesis can I come up with which is consistent with this prima facie inculpatory item of evidence? Under what story or narrative would finding this item of evidence or observing such and such fact be plausibly interpreted as exculpatory, in spite of its preliminary inculpatory reading? In addition to the guilt hypothesis I have been working with, which innocence-pointing theory of the case allows me to predict that an item of evidence such as the one I had just collected would have to be found if that theory was true? If hypotheses, theories, stories or narratives like the ones involved in the previous questions can be suggested and seriously entertained, this should sound the alarms indicating the available evidence at this point is not enough to satisfy the BARD standard. More has to be done, and that is to keep drawing predictions from the innocence-pointing theories and to determine whether they are confirmed. This feature may strike you as an unfair and perhaps unrealistic load put upon investigators' and prosecutors' shoulders. While that may be true, it simply, but importantly, reflects society's supposed preference pertaining to how factual errors, such as false convictions and false acquittals, should distribute in the long run. Put differently, if it is really true that we consider false convictions an egregious type of mistake as compared to their counterparts (false acquittals), we should take steps to make it much more likely that if and when the justice system fails, it does so by incurring more abundantly in false acquittals (or the lesser harm) rather than in false convictions. Deciding to set in place a very demanding standard of proof (such as BARD, coupled with the epistemic-intersubjective interpretation of it suggested in section 1) is precisely the most important of those steps (which is not to say that it is an infallible measure to achieve the desired distribution of errors).

\section{Conclusions}

a) I have directed the reader's attention to the fact that, apart from the notion that it requires the trier of fact to be very sure regarding the accused's guilt if a conviction (instead of an acquittal) is in order, the BARD standard of proof remains not only unclear, but susceptible to be subjectively interpreted, which has negative implications for due process, legal certainty, and uniformity in criminal adjudication across similar cases.

b) Against this background, I introduced Professor Ferrer's approach regarding the epistemic-intersubjective content of the BARD standard, and suggested we adhere to it, mainly due to its potential to become the system's rationality touchstone in terms of providing triers of fact's, investigators', and prosecutors' fact-finding efforts with a more reliable basis. 
c) I also discussed other proposals to endow the BARD standard with non-subjective content, and argued that Ferrer's is a more suitable criterion in that it accurately specifies the basic intellectual operations common to these standards. These operations consist of generating and severely testing hypotheses.

d) I proceeded by briefly exploring the nature of hypotheses generation and linked this cognitive process to Peirce's known analysis of abductive reasoning.

e) Finally, I elaborated on some prospective considerations specifically related to the Mexican criminal justice system, which despite its recent reforms, still carries a heavy burden amounting to an authoritarian model of criminal investigation that we need to be able to progressively dismantle.

\section{REFERENCES}

Bayón, J. (2008). Epistemología, moral y prueba de los hechos: hacia un enfoque no benthamiano. Analisi e diritto, 15-34.

Carson, D. (2013). Investigations: What could and should be taught? The Police Journal, 86, 249-275.

Carson, D. (2009). The Abduction of Sherlock Holmes. International Journal of Police Science and Management, 11(2), 193-202.

Carson, D. (2007). Processes: Proving guilt, disproving innocence. In D. Carson et al., Applying Psychology to Criminal Justice (pp. 233-250). John Wiley \& Sons.

Ferrer, J. (2007). La valoración racional de la prueba. España: Marcial Pons.

Findley, K. (2006). The multiple dimensions of tunnel vision in criminal cases. Wisconsin Law Review, 2.

Laudan, L. (2013). Verdad, error y proceso penal. Un ensayo sobre epistemología jurídica (trad. Carmen Vázquez, Edgar Aguilera). España: Marcial Pons.

Pérez Correa, C. (2015). De la detención a la prisión: la justicia penal a examen. México: CIDE.

Picinali, F. (2015). The threshold lies in the method: Instructing jurors about reasoning beyond reasonable doubt. International Journal of Evidence and Proof, 19(3), 139-153.

Rassin, E. (2010). Blindness to alternative scenarios in evidence evaluation. Journal of Investigative Psychology and Offender Profiling, 7, 153-163.

Rassin, E., Eerland, A., Kuijpers, I. (2010). Let's find the evidence: An analogue study of confirmation bias in criminal investigations. Journal of Investigative Psychology and Offender Profiling, 7, 231-246.

Rossmo, K. (2009). Criminal investigative failures. USA: Taylor \& Francis.

Woods, J. (2015). Is legal reasoning irrational? An introduction to the epistemology of law. United Kingdom: College Publications.

\section{Notas}

[1] A standard of proof is a rule that establishes (or is supposed to establish, see section 2) the amount and quality of evidence needed to assert some proposition as proven.

[2] The trier of fact is the individual or group of individuals mainly in charge of making factual determinations based on the available evidence in the context of legal proceedings, mostly, trials. 
[3] And something of the sort happens with other terms such as "full proof" or "intimate conviction", used in continental or Civil law legal systems as an effort to come up with synonymous expressions in order to clarify this requirement.

[4] Even if that means we falsely acquit a vast proportion of felons, which is something that gets obscured by our protective anxieties. This is why the standard of proof must be properly conceived, in principle, not as an error-reduction tool, or, in other words, not as a devise suitable to reduce the two paradigmatic types of epistemic errors a criminal justice system may commit, i. e., false convictions (also known as false positives) and false acquittals (also known as false negatives); but as a tool for distributing such mistakes in a certain way, for instance, 2 or more (usually more) false negatives for each false positive. The phrase "beyond all reasonable doubt" purports to function as the criminal standard of proof, and if adequately interpreted and applied as a very exacting threshold for evidence sufficiency, it is believed that it contributes to materialize in the long run an error distribution ratio of 9 to 10 false negatives for each false positive. Suggesting that we put in place an even more demanding standard, as some scholars do, will likely have the effect of increasing the number of false negatives for each false positive. The main question at this point is this: ¿Are we really willing to be that indifferent towards false acquittals? Put differently, ¿do we really want to pay such a high price in exchange of making false convictions even more infrequent? My personal inclination is to favor a negative answer to the previous questions, but regardless of what I think, it should be stressed here that these are matters of a political-morality nature, that have to be discussed, and hopefully settled, in the public sphere.

[5] Except, of course, for those predictions of certain pieces of evidence that allow us to come up with innocence-pointing hypotheses in the first place; predictions which may also be drawn from the guilt hypothesis. I owe this observation to Professor Jordi Ferrer, for which I am thankful.

[6] Or, more precisely, in intersubjective terms.

[7] An example of this situation could be not having found the firearm with which the accused allegedly (according to the prosecution's theory) killed her victim, or not having found the accused's fingerprints in that firearm. Both elements, that a firearm would have to be found, and that said firearm would have to contain the accused's fingerprints, are predictions that a reasonable person may draw from the guilt hypothesis that someone killed her victim by shooting her, for instance, in the chest. Leaving these expectations unsatisfied is a sign that the hypothesis under scrutiny has not passed the test we have put it to.

[8] An example of this situation could be having identified credible witnesses stating that the accused was with them by the time the murder took place, coupled with, for instance, CCTV footage showing the accused arriving and leaving some place very distant from the murder scene, hence making it very unlikely (if not, impossible) that she could have killed the victim. That we will be able to find these evidential items are reasonable predictions someone could draw from the innocence-pointing hypothesis that postulates an alibi for the accused, that is, that she was in another location (may be very distant from the murder scene) by the time the crime took place.

[9] An example of this situation could be that certain plausible lines of inquiry were simply not investigated by the police or the relevant investigative authorities. For instance, if under the circumstances of the case at hand, it could be determined that other people had a significant motive, and/or the opportunity to commit the crime, not having established where they were and what they were doing by the time of the murder, counts (or should count, according to the interpretation of BARD presented in section 1) against the investigative authorities in the sense of making an acquittal the legally required verdict. This is because by not following such lines of inquiry, when the case moves forward to the deliberation stage (something that should have not happened, see section 5 of this essay), the trier of fact is left with no information to determine whether other plausible theories consistent with the accused's innocence are confirmed or not. Again, according to the standard outlined in section 1, this scenario amounts 
to the existence of a reasonable doubt. But keep in mind that the existence of a reasonable doubt is still compatible with the guilt of the accused; in other words, the emergence of a reasonable doubt in the prosecution's case is not a conclusive demonstration of the accused's innocence (just as reasonable doubts being non-existent in the case at hand is no conclusive demonstration of the accused's guilt). The requirement that there be no innocence-pointing hypothesis left standing only shows how serious a mistake our societies take false convictions to be. These errors are so serious that we tolerate in exchange many likely felons to be entitled to an acquittal.

[10] By clarifying the BARD standard of proof in the right direction I mean that these proposals point to the features the evidence against the accused should have or to the inferential processes the trier of fact should engage in when she goes about assessing the evidence.

[11] I am using the expression "agent" in its philosophical sense (someone possessing the attribute of agency), not in the sense of someone performing some police or other security related function.

[12] This is why it is said that abduction is an ignorance-preserving cognitive heuristic. Nonetheless, I prefer to follow the suggestion to call it an ignorance-eroding heuristic (Woods, 2015: 211-214), because even though the agent that has come up with some hypothesis is not yet justified in believing it, in that hypothesis lies an initial cognitive achievement from which to move forward in the quest of more ambitious doxastic attitudes.

\section{BY-NC-ND}

